\title{
La ética y los medios de comunicación
}

\author{
Freddy Álvarez*
}

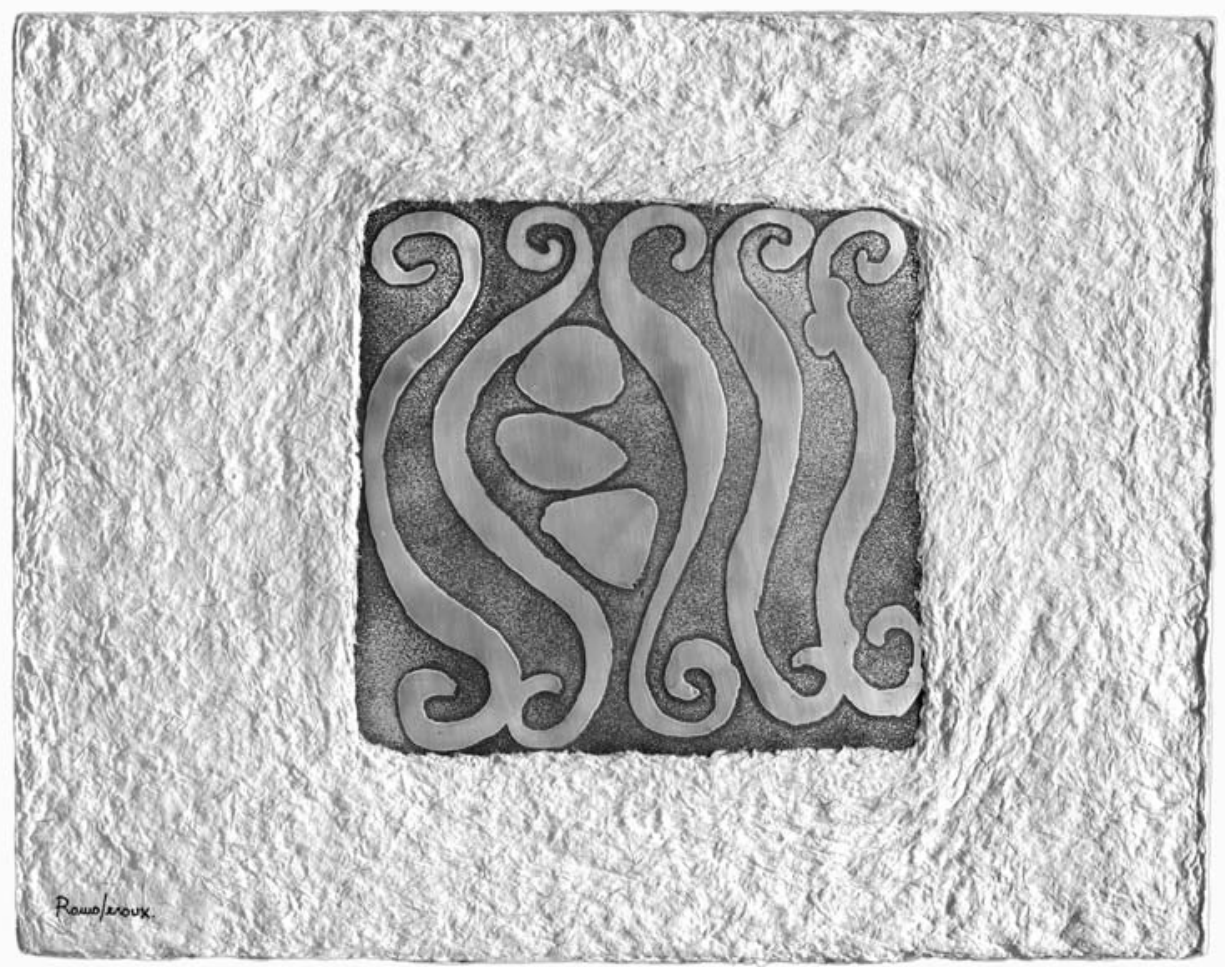

Paz para hoy

\section{Preámbulo}

Preguntarse por la ética y los Mass Media, no es fácil. Es una interpelación impregnada de complejidad por la pluralidad de los Media, uni- da a la dificultad para entender un fenómeno relativamente actual. Además, para lograr acercarnos a una repuesta seria y profunda es importante replantear la ética de otro modo. Los Media, en tanto que tecnologías, como todas las ciencias,

* Doctor en filosofía por la Sorbona (París VIII). Profesor investigador de la Carrera de Comunicación Social de la UPS y autor de artículos y publicaciones varias sobre filosofía, conocimiento y desarrollo. 
debido a la influencia del cartesianismo, han estado fuera de toda relación ética. Quienes los manejan, todavía creen que por pretender a la objetividad y a la neutralidad ya están en la ética. Veamos un poco las derivas en las que ingresan los Media a causa de su disyunción con la ética y los grandes olvidos en los que ha caído, sobre todo en lo que se refiere a la ética y a la verdad.

\section{Los medios y la comunicación en- tre el bien y el mal}

Los Mass Media se encuentran en el ojo del huracán. Algunos todavía piensan que los Media dependen de quien los utilice. Al respecto, existen tres posiciones que son bastante corrientes:

Primero, quienes piensan que los medios de comunicación son claves en la organización de cualquier civilización; bastaría con mostrar los inminentes cambios que se provocan con la implementación de los nuevos medios. Estar en el "boom de la comunicación" corresponde perfectamente a uno de los niveles ascendentes del "progreso". Los medios de comunicación pueden ser vistos como el signo evidente de una nueva época.

Segundo, hay quienes consideran que los medios de comunicación son el inicio del fin -frase utilizada por Jean Baudrillard-. Los medios de comunicación son el inicio de la destrucción, el ocaso de la civilización y la muerte del sujeto. Se trata de una visión apocalíptica.

Tercero, hay quienes piensan que la influencia de los medios y los cambios en la sociedad siguen dependiendo del uso que les den quienes se sirven de ellos.

Más allá de esta distinción, el problema es que las posiciones se polarizan cada vez más. Veamos algunos de los matices de tales argumentaciones.

Una sociedad globalizada produce un universal sin totalidad, afirma el filósofo ficcionario, Pierre Levy. La universalidad de la modernidad estaba contenida en sus promesas de la razón, el progreso y el desarrollo. Las universalidades, sin embargo, nunca fueron universales y su llenura aparece ahora como un fiasco. La totalidad hegeliana lograda por la dialéctica no arribaba al respeto de las singularidades, como bien lo expresa el filósofo argentino Enrique Dussel. La universalidad fue más bien el triunfo de una particularidad, afirma el lingüista Todorov. Los media nos han dado una abundancia real, sin término, con la sensación de incompletitud. Por primera vez sabemos que la abundancia no es llenura. Con la precariedad de los media el universal ya no está lleno, como aparentemente se creyó. En otras palabras, tal como afirma Baudirllard, los sistemas obesos de información son iguales a la nada. No tenemos el sentimiento de estar en el pecado capital, pues el exceso en la obesidad hambrienta no es un pecado, es la falta que sigue en la carencia. Aunque las comunicaciones se extiendan al infinito, el sentimiento de vacío es inevitable. Las asimetrías se amplían, por ello no podemos decir que estamos en el final. Podemos intentar romper la frontera, ampliar el margen sin que podamos decir que hemos logrado hacer todo lo que queríamos o que el borde ha sido integrado en sus expectativas. Más bien pareciera que los bordes han sido tomados en cuenta para decretar su inexistencia definitiva, porque el problema ya no está en los marginales sino en los excluidos aunque no sean marginales. En fin, los sistemas pueden crecer en la voracidad ligada al hambre y con el hambre de la abundancia acrecentar las asimetrías. Así, lo incompleto es lo no-total perteneciente a la abundancia de la mediocridad y a la marginalidad de la exclusión.

Ahora vivimos en una nueva y original forma de conocimiento: el conocimiento sin totalidad. Los conocimientos pueden ser infinitos. El infinito de las informaciones ya no puede ser recibido como en la no-receptividad de la finitud de lo mismo, pensaba Levinas, sino que el infinito es finito, a pesar de la medida de su obesidad. Las dificultades no están fuera del infinito sino en el infinito mismo. Siempre pensamos que el infinito es la totalidad. Sin embargo, lo infinito es lo in- 
Todo vale porque todo cabe en una universalidad que no tiene fondo, no por profunda, sino por epidérmica, dermatológica.

completo y la suspensión de la totalidad. Ergo, si algo puede ser infinito es por ser incompleto.

La nueva universalidad sin totalidad es un diluvio, el segundo diluvio dice Levy. Todo cabe, la derecha y la izquierda, las mujeres y los fascistas, la mediocridad y las matemáticas. Todo puede ser una gran aglomeración, de todo para casi todos. No importa lo que seamos o queramos ser: un crítico social dedicado a depilarse las uñas y comer caviar. Un neoliberal que por la noche cuenta poemas a sus hijos después de haber explotado durante catorce horas a cientos de personas. Un travesti que dirige un banco. Un comerciante que estudia filosofía, o una filosofía hecha para vender Coca-Cola. Un hombre público con perversiones que las sacia en las páginas de los pedófilos. La cibercultura es un nuevo diluvio. Todos los animales entran en la barca, todo enemigo ha de ser tomado en cuenta. Una página para la guerrilla, otra para los paramilitares, otra para los violentos sin causa. Los mercenarios se confunden con los ideólogos. Se puede hacer filosofía hasta para matar a la filosofía. Todo vale porque todo cabe en una universalidad que no tiene fondo, no por profunda, sino por epidérmica, dermatológica, pues como diría Gilles Deleuze siguiendo a Nietzsche, lo más profundo está en la piel.

En efecto, la WEB no está encerrada semánticamente en el tiempo. Los cierres son juegos que se establecen para cernir identidades y congregar categorías. La apertura es un candado segregacionista. Pareciera ser una autoridad central, sin ningún llamado al orden. El segundo diluvio sucede en la sociedad informacional. Se trata de un desorden para lo mejor o lo peor. No hay nada que nos lleve a tierra firme o a paisajes estables. Todo puede ser visto, pensado, imaginado, dicho, cuando ya nada podemos decir, ver y pensar. En efecto, pensar es un lujo en una sociedad de experimentación como la nuestra.

El punto de quiebre acontece en el siglo XVIII, donde nos encontramos con un equilibrio frágil. El antiguo mundo con sus bellos fuegos y las humaredas de la revolución industrial cambió el color del cielo. Diderot y D'Alambert lograron publicar la Enciclopedia. Todo lo que queríamos saber lo podíamos encontrar en un libro. No cabía duda sobre tal absurdo. Se esperaba la dominación sobre el saber, saberlo todo y sobre todo. El conocimiento se debía terminar. No sabíamos sobre su final cuando todo podía ser dicho. El final del conocimiento estaba en la constatación de un abarcamiento sin límites. Llegamos al final del conocimiento sabiendo que no podíamos abarcarlo.

La totalidad se pierde cuando el mundo se amplía. El siglo XIX amplía el mundo, hay un descubrimiento progresivo de la diversidad, hay un crecimiento de los conocimientos científicos y técnicos. Desde ese momento sabemos que ni un grupo, ni un individuo, ni un universal pueden dominar el conocimiento. Cualquier dominio es una ilusión o una mentira enunciada desde el poder. El conocimiento es intotalizable e inmanejable. En el ciberespacio el todo está fuera de la lista de espera. No hay como saber absolutamente. De esta manera, de la gran arca hemos pasado a una flotilla de arcas, con sus pequeñas totalidades, diferentes, abiertas, provisionales, piensa Levy. El nuevo conocimiento es producto de la navegación del surf. Somos surfistas en la actualidad de la despolítización de la reflexivización global, en el caos, en los desequilibrios absolutos demandado orden, sin certezas, en las equivocaciones continuas, y convencidos que esto es lo más correcto y veraz.

Ahora el saber universal sin totalidad es re-estructurado en redes. Redes que conectan nuevos puertos y enredan otros. Sólo bastaría con entrar al sistema para que el milagro ocurra. El sistema ayuda a condensar la memoria y a ga- 
rantizar su dominio intelectual, sin embargo es la red la que domina. La nueva memoria son los grandes bancos de datos. La memoria histórica es reemplazada por las nuevas memorias tecnológicas. La desterritorialización de la biblioteca es, paradójicamente, el inicio de un gran silencio. Todos pueden hablar de todo sin fundamentos y profundidad a pesar que el todo se refugie en la incompletitud. El saber es soportado por los TIC's y ya no por las colectividades humanas; el saber ya no pertenece a los sabios o a los científicos, como nunca ha pertenecido a las comunidades ancestrales, ahora el saber pertenece a las máquinas.

El mecanismo del conocimiento ya no tiende a los conceptos abstractos. El mecanismo era la abstracción teórica, hoy se tiende a las cartas finas de singularidades, a una descripción detallada de los grandes objetos cósmicos, de los importantes fenómenos de la vida, de la actualidad siempre vieja de la guerra. Describir es conocer; informar es saber; hablar de lo mismo es diferenciarse. La instrumentalidad es el menú del día.

El espacio euclidiano se ha roto; se rompe el espacio con el precio del tiempo. Nace el espacio topológico con el cual se puede hacer topografía sin geografía. El espacio topológico es una liberación del espacio y el tiempo, una emancipación de la materialidad bruta. El espacio topológico no es una sustitución. No es porque escribimos que dejamos de hablar. La escritura no sustituye al hablar. No es porque hablamos por teléfono que dejamos de encontrarnos. El espacio topológico es la complejización de la ecología de transportes. No es el cambio de un medio por otro. Se escribe de otra manera desde que se envían telecopias. Se escribe mucho más desde que se tiene el correo electrónico. Se experimenta sin compromiso desde el momento que tenemos el mundo frente a nuestra mirada.

¿Cómo llegamos a estos espacios? La comunicación comenzó con un dispositivo mediático. El emisor de prensa, radio, TV, alcanzaba a un gran número de receptores aislados, disper-
Miles de personas construyen el mundo virtual; es todo un movimiento social: estar conectado es el imperativo categórico kantiano de los tiempos contemporáneos.

sos, pero en ellos no había regreso ni reciprocidad. Muchas personas se representaban el mensaje si compartían el mismo sistema. Un segundo dispositivo es la carta y el teléfono. Existe una verdadera reciprocidad pero únicamente de punta a punta. Sólo entre individuo e individuo. Un tercer dispositivo busca un mayor contexto común, una comunidad que no es producida por especialistas. Miles de personas construyen el mundo virtual; es todo un movimiento social: estar conectado es el imperativo categórico kantiano de los tiempos contemporáneos. Supuestamente nace una inteligencia colectiva, construida por relaciones transversales no-jerárquicas. ¿Qué tan cierto es esto? ¿No es acaso que los $\mathrm{Me}$ dia crean una gran fantasía desde la cual no se puede ver ni sentir la crueldad de la razón comunicativa?

La nueva democracia nos hace olvidar los desmanes de los fanáticos de la democracia. La ingenuidad de los comunicadores es evidente. Pierre Levy dice que los nuevos sistemas son el apoyo para una democracia directa con el máximo de inteligencia colectiva de la civilización. Tener un celular y una computadora conectada al internet es estar en la cultura, comenzar definitivamente la democracia y aprovechar de sus beneficios modernos, que locura y atrocidad.

Los primeros grandes cambios fueron las invenciones de la agricultura, la maquinaria increíble de la ciudad y el Estado. Ellos fueron un cambio en nuestra relación con el mundo, en la manera de percibirnos con otros y nosotros mismos. Una segunda mutación es el universo industrial. Se unifica la tierra por los medios de transporte y el desarrollo del mercado. Se en- 


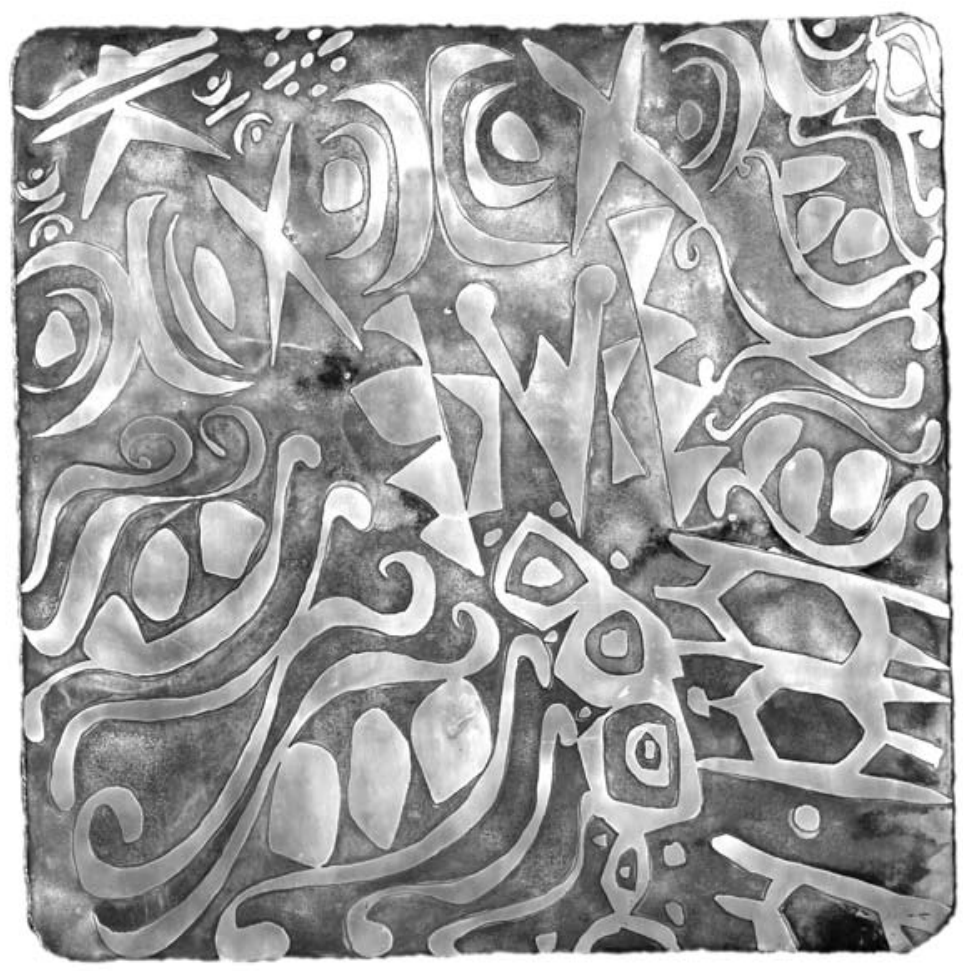

Qué devolvemos a la naturaleza. Detalle

mayor cinismo ético: esto que pasa no tiene que ver con nosotros.

¿No es está una ilusión escéptica? ¿No es éste el universal de los medios, de las técnicas? ¿Podemos estar seguros que una técnica pueda crear un universal? Las técnicas abren las posibilidades o ¿son los actores históricos los que hacen la universalidad? Para algunos hay democracia porque hay alfabeto. El medio hace posible la condición. La Internet es un medio donde cualquiera puede comunicarse y no hay ningún Estado que interfiera. Nos podemos comunicar sin que un editor o productor lo impida. La revolución francesa y americana no eran pensables antes de la llegada de la prensa; una vez inventados los periódicos, ellas fueron inevitables. El medio es el mensaje, dirá el filósofo canadiense Mcluhan.

Oponerse a los medios es volver al totalitarismo. Supuestamente, no hay ningún problema de manipulación ni de poder detrás de los medios. Ellos afirman que son las sociedades y los regímenes totalitarios los que han detestado los

gendra la laicidad. La tercera mutación es la des-territorialización del conocimiento por el desarrollo de la comunicación. Si antes el conocimiento sin mayores modificaciones se ejercía hasta finales de su vida, éste se transmitía a sus hijos, influía en varias generaciones, ahora una sola generación está afectada por rápidos cambios en los conocimientos. La biodegrabilidad del conocimiento es más evidente. La rapidez de los cambios nos despoja de toda certeza e impiden la respuesta inmediata a la pregunta ¿quiénes somos? Por tal motivo, ya no nos interesa el saber sino el hacer y el hacer con el saber. El por qué aparece como una pérdida de tiempo. Todo se resuelve en el cómo sin tener conciencia del por qué, debido a que se cree que el cómo tiene la magia de todos los por qué. Además, la multiplicidad de sentidos sin relación son las fragmentaciones que nos sitúan en el medios de comunicación. Mussoline y Stalin tenían como único medio a la radio. En su tiempo, las máquinas de escribir fueron confiscadas con el papel carbón. Las fotocopiadoras fueron encarceladas. En este sentido pensamos en la necesidad de que haya TV no unidireccional sino TV por satélite. En el momento en que existe el fax y el micro ordenador, esos regímenes se debilitan.

Levy habla de una inteligencia colectiva que nace en la virtualización debido a las redes que se establecen entre los seres humanos. Esta es una idea muy común. El ecologista Lovelock hablaba de ella con su hipótesis de la GAIA. Joel Rosnay, biólogo, ve en las redes la emergencia de un mega-organismo. Marshall Mcluhan y sus sucesores hablan de un sistema nervioso planetario. Douglas Rushkoff se refiere a la llegada del cerebro global. La inteligencia colectiva está centrada en la persona. Hay una inteligencia emer- 
gente del colectivo y ésta es un beneficio para la humanidad.

Por el contrario, la euforia de los medios es contrastada fuertemente por sus efectos. No podemos olvidar que todo medio de comunicación crea nuevos excluidos, por ejemplo, el alfabeto crea el analfabeto. Sergio Latouche piensa que estamos embarcados en un vehículo que ha perdido su chofer. Tendemos al colapso y estamos frente a un precipicio. Esto se lo debemos a la tecno-socio-economía. Para Latouche, el mundo ha alcanzado el frenesí del carácter mecánico. Los seres humanos hemos devenido ruedas de ese mecanismo. Lo social ha quedado absorbido en la tecno-economía. Las leyes de la técnica y de la ciencia se encuentran por encima del Estado. La capacidad de legislar se reduce. El crecimiento del poder de la técnica lleva a la abolición de la distancia, a la emergencia de la Aldea y la caída inmediata del espacio político. La desaparición de la distancia crea la desaparición del espacio nacional, provoca la emergencia del caos que destruye la base del Estado-Nación y engendra fenómenos de descomposición, nacionalismos, etnicismos, racismos, xenofobias. La economía se transnacionaliza. Ella ya no es autocentrada, es extrovertida. Además, la división del trabajo se internacionaliza. Por último, la autonomización de la economía hace que lo social se vacíe de toda sustancia.

A los mecanismos y automatismos se les ha colocado nuevas ruedas. Los consumidores, condicionados por la publicidad, responden a demandas del sistema de producción, así como los productores reaccionan a las obligaciones y señales del mercado. Los ingenieros contribuyen al crecimiento de la técnica. Las técnicas siempre están llenas de medios que despojan al individuo del dominio de su propia vida. Los responsables políticos son redes de este mecanismo. De hecho, la política se transforma en un mercado.

Los mass media crean esferas transnacionales. La velocidad de los media hacen arcaicas las reglamentaciones nacionales y exigen una organización mundial. El anonimato generalizado de las mega-máquinas tecno-societales desmoraliza las relaciones sociales y políticas. De este modo se abandona toda consideración ética cuando la eficiencia es el único valor reconocido por la máquina anónima.

Estas máquinas han devenido algo no dominable. Una de las consecuencias es el fin de la política, es la pérdida del dominio sobre su destino por las colectividades en provecho del crecimiento de una administración tecnocrática. Dicha uniformización no sólo funciona con la unificación sino también con la exclusión. Asistimos a una universalización planetaria de modos de vida, a una dictadura de la mediocridad, a la exaltación de lo banal. Además, cuando los seres humanos más se parecen, más odios aparecen, puesto que las diferencias persisten en la identidad.

La dinámica tecno-económica desraíza a los pueblos y conduce a una desculturización dramática. La pérdida de identidades culturales, el desencanto del mundo, la exclusión económi$\mathrm{ca}$, favorecen el desamarre desesperado de explosiones de identidad. Lo político queda desposeído del saber del poder y del decir. El único lugar de ciudadanía pasa a ser la empresa.

Baudrillard plantea una serie de tesis premonitorias que insisten en la fatalidad que acecha a la tierra. Para él, este tiempo es el "tiempo del descuento" -el juego llega a su fin-. Son los segundos de la pantalla en permanente titileo, es el último respiro de opción antes de la barrida final a consecuencia de la tecnología.

"Lo actual" de los medios de comunicación es un registro en relación con un hecho y "fuera de foco" con respecto al espacio y el tiempo. Existe una gran diferencia entre el acto y el hecho actual. Existe una transmutación en cuanto a un espacio y un tiempo. No es el problema del periodista. Es un claro síntoma entre la desigualdad por identidades diferentes en tiempos diferentes. Además, "lo actual" está determinado por el poder. Entre "lo actual" y lo "factual" no hay relaciones de naturaleza, no hay una historia lineal como para la historia clásica. Sólo existen relaciones de naturaleza. El acto y el facto se en- 
cuentran en un mismo orden y en una misma distancia.

El efecto de tal separación es la configuración de unas masas que no tienen una historia para escribir, ni pasado, ni futuro, no tienen energías virtuales para liberar, ni deseo para realizar. Su fuerza es actual, presente y autosuficiente. El único sentido de las masas es dejarse desentrañar por los profetas del devenir y por los efectos tecnológicos. Las masas tienden a ser gelatinosas, imbuidas en la cultura del simulacro. Habitamos en una guerra semiótica que se ha encargado de borrar los significados de la existencia social.

El único fin de la simulación es el instrumental. La simulación tiene un carácter de premeditación, esto la hace racional. Ella conoce el objeto para posteriormente pasar al efecto de simulación. La simulación es el fin en sí mismo. Ella es la conducta inevitable para los que están sumergidos en una realidad sin certezas. La simulación es del orden de la alteridad absoluta, como causa y como destino. No se acepta el origen constitutivo de los acontecimientos. Ella es la negación simultánea de los hechos. La simulación supone un ir más allá de su objeto. El orden y la ley no son más que simulación. La alteración absoluta de lo real nos lleva a un estado de indiferenciación. Lo real se desintegra como en un juego electrónico.

Por los medios de comunicación hemos logrado una masificación uniforme de conductas y actitudes. Lo humano vive colectivizado por el tejido umbilical electrónico. Para Baudrillard todos los hombres nos encontramos ligados a algún tipo de tecnología por acción o por omisión. Por acción, el sujeto forma parte de su propia condena y es doblemente culpable. Goza del privilegio de la elección y actúa de acuerdo a ella. El sujeto conoce cuál es el camino que conduce hacia la masa que lo espera. Por omisión, el sujeto es inocente, él no eligió ser atravesado por la tecnología, pero no puede escapar a la desgracia de ser alcanzado por sus efectos. El camino hacía la masificación tampoco puede ser mitigado por ninguna razón (económica, social, cultural o geográfica). En fin, nadie escapa a la lobotomía colectiva de la independencia, los únicos que pueden escapar son quienes no han nacido en este planeta.

La masa es una entidad vacía en sí misma, entre ingenua y voraz, gracias a la tecnología. Sus significantes son ajenos, por ello adquiere el status de una maravillosa gelatina adherible a toda situación. Lo social no será sino un slogan sociológico, una fórmula de comprensión, una entelequia en manos de la masa. Lo social vive herido de muerte por la masa. Lo social desaparece por la variedad nueva dentro de un universo simbólico. La masa será alguien capaz de engullirse todo lo social. La masa no ocupa ningún lugar, es multiforme en los caminos de la significación sin contenido, sin significado, sin objetivo, sin destino. Consumida por lo espectacular. Como cuerpo no existe, por eso sólo se le puede rastrear por sus signos.

Las info-rutas no pueden ser pensadas como una nueva forma de hacer sociedad, afirma Pierre Levy, es necesario verlas al servicio del capital. Las info-rutas son infomerciales, escenarios de publicidad, cadenas temáticas al servicio de anunciadores. Las tecnologías de la información son utilizadas por la economía capitalista, por la emergencia de una economía mundial con funcionamiento instantáneo.

Ahora nos situamos en el tiempo del instantáneo permanente. Entramos en un tiempo único, dirá Paul Virilio. Los tiempos mundiales son tomados por slogan. No existe tiempo para

Por los medios de comunicación hemos logrado una masificación uniforme de conductas y actitudes. Lo humano vive colectivizado por el tejido umbilical electrónico. 
la reflexión. La interactividad sucede con la pantalla, con los datos colocados como autoridad, con los pares, por los expertos.

Deleuze afirma que la virtualidad se opone a la actualidad y no a la realidad. La virtualidad está compuesta de realidad. La realidad está compuesta de virtualidad y actualidad. La mundialización de la virtualización está estrechamente unida al desarrollo de los Mass Media. Todo empieza con el teléfono. Hoy arribamos a la tele-audición, a la tele-visión, a la tele-acción y a la tele-olfatación. Estamos en la virtualización del sonido, de la visión del cuerpo porque se puede tele tocar, tele sentir, tele amar. El mundo de la virtualización produce desempleados que viven en la virtualización del mercado.

El confort es una virtualización con respecto al cuerpo. Sin embargo, con la virtualización global no hay necesidad de cuerpo. En el momento en que el hombre y la mujer devienen numéricos, no son necesarios para la destrucción. Con la virtualización no queda nada de la realidad activa del cuerpo. El cibersexo es una forma de eliminación del cuerpo, se asienta en la promesa que se puede amar lo lejano como a sí mismo -intención de Nietzsche- Se pierde el cuerpo en orden a las impulsiones o las ganancias de la electricidad sexual, como lo decían los futuristas. La electricidad es el futuro, es la caída definitiva del cuerpo. Desde ahora, el amor entre seres puede ser teleguiado por la electricidad.

El ser humano en la virtualidad es un inútil como procreador, como productor, como destructor. Hay crímenes tecnológicos donde el cuerpo no deja huella. Baudrillard piensa que $l a$ Guerra del Golfo nunca ocurrió porque fue dirigida por la realidad virtual. Antes el sujeto estaba en el mundo, se fundía en el medio ambiente. Hoy, el sujeto se separa del medio ambiente. La tecnología se pone por encima de la ética y el sujeto no vive ninguna regulación posible.

En la ciudad real hay un centro y una periferia. Para el urbanismo virtual el parámetro máximo es lo lejano. La ciudad aparece a domicilio. El noticiero de la noche es una plaza pú-

\section{El hombre de hoy va de ciudad en ciudad sin esperar nada, sin intentar descubrir nada. En realidad, hoy aun- que viajemos, no viajamos.}

blica. Nos encontramos con los otros en el domicilio. De esta manera va naciendo el hombre planetario.

El ser humano de la virtualidad no es un nómada. El hombre en el avión, en el tren, en el auto, es un sedentario. Él se fatiga, pero tiende a quedarse fijo. La movilidad no está implicada en el nomadismo. Para ser nómadas es necesario marchar, cansarse. No se es nómada cuando se transporta en vehículo. El nomadismo tiene una dimensión de aventura. El hombre de hoy va de ciudad en ciudad sin esperar nada, sin intentar descubrir nada. En realidad, hoy aunque viajemos, no viajamos.

El gran problema que hemos introducido con la realidad virtual es que la máxima preocupación ya no es la pobreza o el hambre sino la eliminación del otro como ser útil, la exterminación de la utilidad del ser. El Babel inferior era el lenguaje, el Babel superior es la información y la confusión. Shakespeare en Hamlet dice: El tiempo está fuera de sus goznes. El día ya no persigue a la noche. No hay espacio en el cosmos, no existe el afuera. El espacio se encuentra cada vez más limitado a la habitabilidad. Ya no vivimos en el espacio sino en el trayecto de los vehículos, como cuando se va en un TGV, donde no se puede estar en el paisaje a causa de la velocidad. Los nuevos descubrimientos nos han hecho perder la idea de hábitat, de ser en el mundo.

La escala para medir el espacio virtual está en función de la velocidad. Los espacios virtuales ya no se realizan con la escala humana. Dentro del mundo físico, el cuerpo humano era una referencia para la arquitectura. Cualquier espacio, instrumento, era concebido en función de la talla y la morfología del hombre y sus accio- 
nes. En la Edad Media, los constructores hacen sus obras en función de la talla del hombre, de su pie y de su pulgar: el hombre es el módulo. El hombre colocaba orden midiendo y para medir, él utilizaba su pie, su codo, su dedo, "era un mundo organizado a su medida" (Le Corbusier). En el mundo virtual, el hombre está ausente, no hay talla para él ni para sus clones. Se trata de un inmaterial que se desplaza.

El cibermundo es, para Paul Virilio, "la política de lo peor, nacida para hacer ruido". Uno de los temas amados de Virilio es el tiempo. El tiempo es volúmico y no unidimensional, es cronológico, lo cual implica un pasado, el presente y el futuro. El tiempo de las tecnologías es el del teléfono, del fax, de los medias y de la Internet, en una palabra, el ciber-tiempo nos da la ilusión de un mundo abierto sobre el instante del presente inmediato, entregándonos como resultado una "historia sin historia", un tiempo reducido que pasa instantáneamente, gracias a las tecnologías, o mejor, a causa de ellas. Virilio cree que el mundo se nos parece a algo demasiado pequeño por el presente inmediato.

Entre más hay relaciones entre los hombres sobre la tierra no es posible saber lo que se sucede al otro lado del globo y más inconvenientes tenemos para conocer a nuestros vecinos. $\mathrm{La}$ tecnología parece capaz de destruir las relaciones más íntimas entre los seres humanos y coloca en su lugar las relaciones electrónicas, fácticas y superficiales. Extraordinaria contradicción, entre la tierra es más poblada que nunca y las redes de comunicación se multiplican de manera vertiginosa, los seres humanos devienen más solitarios $\mathrm{y}$ aislados que nunca.

Si para Pierre Lévy el crecimiento del ciberespacio corresponde a un deseo de comunicación recíproca y de inteligencia colectiva, la ilusión de las tecnologías, señaladas por Virilio, están en el frenesí por la velocidad, en tanto que poder mismo. Todo poder es freno, sabiduría y aceleración. No podemos entender el poder en términos de represión e ideología. El poder es deseo. Las obras de Foucault y de Deleuze desterritorializan los agentes colectivos de enunciación del poder.

El mito de la mundialización es asesinado: "no hay mundialización, lo que hay es virtualización”. Además, la ilusión es creer que el acercamiento entre poblaciones nos llevará al amor.

Virilio dice que la Internet depende del Pentágono, Lévy piensa que éste no es un producto solitario. Para Lévy, cualquier intento de rebatir los dispositivos de comunicación es un adefesio puesto que se coloca en contra de todos los intereses económicos, políticos y antropológicos. Él sigue la concepción de Deleuze sobre el deseo: "El deseo es el motor y las formas económicas e institucionales le dan forma, la canalizan, lo refinan" (Anti-edipo).

En suma, los Mass Media se encuentran entre el bien y el mal, por eso la pregunta de si ¿estamos en la verdadera humanidad o en su aniquilamiento total? Preguntarse por la ética en la comunicación es un asunto planetario que desde morales singulares o éticas parciales no es posible contestar. ¿Qué está pasando? ¿Qué desearíamos?

\section{Ir más allá del bien y del mal}

En la pregunta sobre la relación entre ética y medios de comunicación nos encontramos con el a priori trascendental de las intenciones. No se puede hacer el juicio ético por el uso o mal uso de los medios de comunicación, el campo ético mediático se sitúa más allá de las intenciones ¿Cuándo algo es malo o bueno? Cuando tenemos la intención de hacer el bien o el mal, diremos desde el siglo XIV con la ética de Pedro Abelardo. La acción no importa, lo que importa es la intención. La intención es el determinante del acto ético. El derecho fue impregnado por esta ética: sólo hay delito cuando se tiene la intención de realizarlo. Por ejemplo, con la afirmación que está hoy de moda: "se recibieron dineros, pero no se sabía que provenían de un presunto narcotraficante, entonces no se cometió ninguna infracción". Aquí, las intenciones se demuestran a través de averiguar 
sobre sí hubo información o no. Luego, haber conocido es constatar la intención. Entonces, los ignorantes no pueden ser culpables de las intenciones que nacen en la información y los tontos son quienes quedan mejor librados de pecado y de culpa o de responsabilidad. El problema se agudiza cuando nos atrevemos a cuestionar esta forma de la ética. Así, el cuchillo no es bueno porque corta la carne en la cocina o malo porque le cortó la mano a cualquiera. Esa modalidad ética es muy imprecisa. Los medios tienen sus efectos más allá del uso o abuso de los sujetos. No queremos decir que estamos confrontados por una ética sin sujeto. La crítica está puesta en las intenciones. El aditamento de la antigua fórmula es doblemente conflictivo por la organización de las disciplinas.

Pero las intenciones no son el único a priori. La pregunta ética se instala en un mundo Neoliberal y globalizado. Hoy la preocupación ética parece ser una preocupación universal. Todo el mundo se refiere a la falta de ética en casi todas las instancias. Sin embargo, encontramos algunas contradicciones sobre todo desde el horizonte de la corrupción: Les exigimos ética a las personas cuando los principales valores que la cultura ha construido son los económicos. Zizek dice que la economía es lo real y la política un teatro de sombras. Tener más, consumir más, gozar más son objetivos de una sociedad que también quiere ser ética. Aquello que se presenta como ideal, siendo contrario a la ética, es lo que se quiere moralizar cuando existen asimetrías y culpabilidades profundas. Se insiste en que el único dominio posible es el de las privatizaciones y nos quejamos por la ausencia de una ética de la solidaridad. Volver a la ética dentro de una sociedad que ha tomado estas opciones es una ilusión. El deber ser de la ética no tiene cabida. En efecto, la ética deviene un asunto de héroes que son éticos por nosotros.

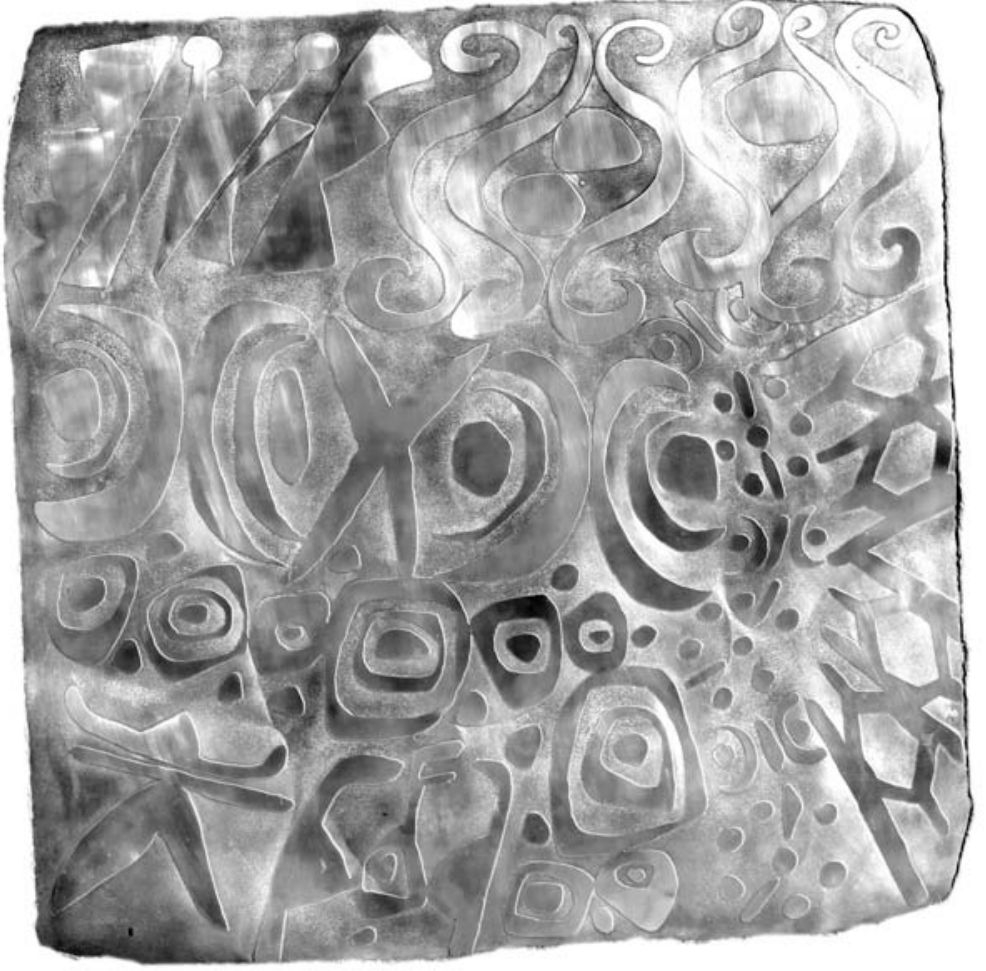

Su alma habita en la luz. Detalle

Pero, ¿qué sucede con la ética en el ámbito de la comunicación? No hay duda que todo debate ético pasa hoy por la comunicación. Junto a la comunicación adviene la noción de imagen. La noción de imagen nos envía a la epidermis de la comunicación, la cual subordina el discurso a la producción del audiovisual. La epidermis cree no oponerse a los discursos de la realidad como si se opone la imagen a la actualidad.

La moral hoy pasa por la argumentación y el consenso. En efecto, el discurso es aprobado por la comprensión. La comunicación está en el corazón de la ética y la ética está en el corazón de la comunicación. Pero en la comunicación está el problema de la mentira, de la manipulación de la verdad, de la información, de la justicia, del ejercicio del poder y del control. Comunicar es persuadir, convencer y esto nos obliga a pensar la ética de otro modo. Por tal motivo, Habermas 
condena la comunicación al quedar en el plano de lo confidencial. Siendo la comunicación tan importante es imposible no reflexionar socialmente sobre ella.

La responsabilidad de la comunicación comienza en la emisión de un mensaje explícito e implícito. Las emisiones se complejizan con la imagen. La preocupación de la imagen pervierte a menudo las preocupaciones éticas en las elecciones. Se pueden evocar los problemas financieros, económicos, políticos, pero muy rara vez las cuestiones éticas. La paradoja está en que a medida que aumentan las grandes inversiones en los $\mathrm{Me}$ dia aumenta la mediocridad en las emisiones y desaparecen los programas difusores de cultura y por supuesto, reflexivos sobre la ética.

La preocupación por el público televidente se realiza bajo el factor de la inversión y de la cantidad de clientes que son los anunciadores. Pero no se puede olvidar que por un lado el ciudadano es el cliente y por otro lado, es el público. Es en ésta ambigüedad donde se reproducen los problemas éticos. Un cliente que no paga no es un cliente, es un público. El cliente en los medios de comunicación privados es quien paga a los asalariados del medio. El cliente no es estrictamente un telespectador. Sin embargo, son los telespectadores quienes justifican un medio. Por tal motivo, pareciera que los medios privados jamás pueden ver en el hombre y la mujer que miran en la TV un fin sino un medio. Además, la satisfacción del verdadero cliente pasa por el público. No olvidemos la afirmación kantiana según la cual desde el momento que el ser humano es considerado un medio, toda moralidad está excluida del acto y de la intención.

El Audiomat no puede versar sólo sobre la medición de audiencia, sino también sobre la satisfacción del público. Pero la satisfacción es la gran trampa de los media. Por tal motivo es indispensable generalizar la cultura y democratizar las opciones. Con mucha razón Habermas decía: "Comprender lo dicho exige la participación y no simplemente la observación".

El convencimiento de los medios no es un acto violento en un primer momento de la co- municación, pero lo puede ser si sólo nos interesa convencer. Convencer por convencer puede estar comprendido dentro de una increíble violencia. El convencer para vencer se mezcla con las agresiones múltiples. Tampoco la comunicación puede ser homologada a un juego de estrategias. Habermas (1989: 162) nos pide no confundir la acción estratégica de la actividad comunicacional: "En la acción estratégica, la una influye sobre la otra empíricamente con el fin de obtener la continuación de la comunicación; cada uno está motivado por el otro para actuar conjuntamente $\mathrm{y}$ es en virtud de estos compromisos ilocutorios inherentes de hecho que proponemos un acto de palabra”. Estrategia y comunicación tienen que ser discutidos en el campo social, ético y político.

Dejar atrapada a la comunicación en el campo de la persuasión o del convencimiento es escapar a los principios de ética. Cuando el único fin es seducir y persuadir al receptor de permanecer en el canal, encadenarlo al medio, estamos fuera de la ética. En este contexto, la ética está siendo aplastada junto con todos los derechos del consumidor. No podemos caer en la creencia de que todos los medios son buenos para persuadir o de creer que la persuasión es un acto bueno en sí. Las vías para convencer han de ser discutidas desde el punto de vista de la ética.

La ética, por tanto, no es un asunto privado que cada uno lo puede decidir de acuerdo a criterios individuales. Pensar en la ética es entrar en escenarios sociales, culturales, políticos y económicos, pero desde referentes muy precisos. La ética es un asunto de muchos. La ética sólo puede ser una exigencia cuando es compartida. Por consiguiente, la ética no es un asunto de imposición de algo que consideramos, de por sí, universal. La universalidad ha de ser discutida, confrontada y reinventada. Ergo, la ética es un producto de la comunicación. Por consiguiente, una ética que se impone es una ética sospechosa y una ética que nace en el lenguaje no es ética pura.

La universalidad de la ética no tiene necesidad de imponerse, pues esto es un contrasentido. No hay porque creer que si no es universal en- 
tonces no se puede ser ético. Badiou habla de universal singular. Las pretensiones de universalidad han de ser dialogadas, discutidas y reinventadas de lo contrario es un universal en entredicho. La pregunta es saber si ¿la comunicación tiene la capacidad de señalarnos los nuevos universales?

En suma, las intenciones no son el problema de los Media, son las lógicas, los valores y aquello a lo que se da valor, los intereses en los que se inscriben y lo que se oculta cuando se hacen visibles ciertas situaciones.

Pierre Bourdieu demostró que la TV es un formidable instrumento de dominación. La TV pertenece, normalmente, a grandes grupos económicos y políticos. Dentro de la TV, los presentadores pueden triunfar sobre todas las críticas. Los medios tienden a ser incuestionables. Es osado criticar un medio de comunicación. Quienes lo hagan, están condenados. Los entrevistadores son pequeños showman que se especializan, en su gran mayoría, en hacer decir a los invitados, lo que ellos quieren que digan. El triunfo de los presentadores está por encima de todas las objeciones. Bourdieu afirma que la TV tiene la imposibilidad de sostener un discurso coherente y autocrítico. En otras palabras, el gran problema de la TV es pensarse a sí misma. Un medio de comunicación no permite críticas.

El juego habitual de los periodistas son los cortes, las interrupciones, los cambios de intereses. Para algunos, el trabajo se parece a una corrida de toros, ser violentos, conducir hacia lo que ellos ya concluyeron desde antes y si no se puede, herir a los interlocutores.

Una de las características ideológicas de la TV global es el silencio o las distorsiones que se les hace a los movimientos sociales. Parece que existiera una incompatibilidad entre los dos bandos. Los argumentos de los presentadores de TV $\mathrm{y}$ periodistas son presentados como dogmas, ellos no se atreven a cuestionar y no permiten que otros los cuestionen. La mayor osadía de la TV está en intentar cambiar las proposiciones por otras. Las imágenes de documentales que sustentan pueden enseñar cualquier cosa y en muchas ocasiones, las conclusiones no tienen que ver con aquello que se discutió. En cierta manera, las reglas del debate son compatibles con la manipulación que se ejerce.

El derecho bueno de la TV para informar y comunicar no deja de ser arrogante, por ello pueden cortar la palabra, decir barrabasadas. Existe una gran equivocación cuando se cree que la TV tiene una gran utilidad y que a través de ella se puede convencer de situaciones más justas, pues el instrumento de manipulación impide cualquier cambio. La manipulación es tal, que lo que se presenta por parte del periodista, bajo la falsa e inexistente objetividad, ya está tejido desde antes en la distorsión.

La TV no permite criticarla porque los dispositivos se imponen a las emisiones y a la crítica de la pequeña pantalla. En suma, la TV como instrumento de comunicación está sometida a una fuerte censura. El periodista impone la problemática a nombre del respeto a las reglas formales y del público. Él representa a la opinión pública e interviene en su nombre con una serie de frases: es qué, seamos precisos, responda a mí pregunta, explíquese, usted todavía no ha respondido, usted no ha dicho lo que le he preguntado. Estas son sus armas gramaticales. Su autoridad dice que la ha recibido de los televidentes, escuchas o lectores. Distribuye la palabra para ser neutral y crea la urgencia para censurar, no deja hablar o increpa, porque dice que los auditores no escucharon. Las intervenciones son diferenciadas.

No se puede obviar que una cosa es hablar a un empresario, al político de su simpatía y otra a un sindicalista o a un indígena o al representante de los derechos humanos. Si el periodista se dirige a alguien importante, tiene una postura del cuerpo, una mirada, un tono de voz, palabras inductoras. Puede dar igual de tiempo a todos los que intervienen, pero dentro de desigualdades reales. Si quisiera ser objetivo habría que asegurar la igualdad a los desfavorecidos cuando en realidad se favorece a los favorecidos. 
El inconsciente de los presentadores y sus hábitos profesionales están unidos a la sumisión cultural a creer que ellos son intermediarios culturales, semisabios o autodidactas. En realidad son los nuevos sacerdotes. Ellos son el audiomat. De hecho, en los problemas sociales ellos son el inconsciente de los privilegiados.

En breve, los Media no democratizan a una sociedad pues, además de jugar con partido propio, pertenecen al poder dominador y brutal. Ellos no aceptan el pensarse a sí mismos a través de la crítica. Son medios de poder al servicio de los poderosos y en orden a tener más poder y defender los grandes capitales y las reglas de su circulación libre.

\section{La neutralidad y la objetividad de los medios en una sociedad de la seducción}

La neutralidad y la objetividad de los $\mathrm{Me}$ dia son imposibles. No hay como ser objetivo y neutral dentro de los medios de comunicación ni fuera de ellos. La objetividad de las ciencias vive entre paréntesis. Sólo se puede pretender ser objetivo sin paréntesis para imponer y creer obediencia dice Humberto Maturana. La verdadera objetividad es la que acepta la parte subjetiva de toda objetividad. Por consiguiente es imposible ser neutral. La ética nos exige tomar partido, comprometernos, no hacerlo es un cinismo.

Las sociedades de la comunicación siguen ejerciendo una increíble violencia por ser obedientes a la cultura de seducción. Por todas partes quiere instruirse un ambiente de proximidad, de ritmo, de solicitud. Hay música e información las veinte cuatro horas del día. La policía abre sus puertas, el ejército se compromete en tareas civiles. Lipovetsky afirma: "La seducción es el proceso general que intenta arreglar el problema del consumismo, las organizaciones, la información, la educación, las costumbres. Toda la vida de las sociedades contemporáneas es desde ahora dirigida por una nueva estrategia que destrona el pri- mado las relaciones de producción en beneficio de la apoteosis de las relaciones de seducción"1.

La seducción a la carta se representa en el espectáculo. En el espectáculo la realidad se convierte en una representación falsa. Así se crea la nueva potencia de la falsedad. El espectáculo no se separa de la dinámica de la alienación. Se seduce y se abusa por el juego de las apariencias. El consumismo revela ampliamente la estrategia de la seducción. El consumismo no se reduce al espectáculo de la acumulación, él se identifica con la sobre-multiplicación de elecciones que hace posible la abundancia. Así, la sociedad posmoderna se caracteriza por una tendencia global para reducir las relaciones autoritarias y direccionales y simultáneamente por el crecimiento de las opciones privadas que privilegian la diversidad y ofrecen fórmulas de programas independientes.

Los comportamientos han caído en la lógica de la personalización. Está de moda la diferencia, la fantasía, desestresarse. $\mathrm{Al}$ respecto Lipovetsky dice: "la seduccion, una lógica que hace su camino, que no escatima nada, y quien, haciendose, cumple una socializacion suave, tolerante, amarrada a la personalizacion -personalizar al individuo ${ }^{2}$.

El lenguaje también hace eco de la seducción, los ciegos son no videntes, los viejos son personas de la tercera edad, las domésticas son gerentes de hogar, a los indisciplinados se les llama niños con problemas. Todo aquello que tenía una connotación de inferioridad, deformación, pasividad, agresividad debe desaparecer para dar paso a un lenguaje diáfano, neutro y objetivo a pesar que la realidad nos sigue mostrando su crueldad.

La seducción no es un proceso de mistificación y de pasividad, sino uno de aislamiento, no por la fuerza bruta sino por el hedonismo, la información y la responsabilidad. Cada persona se convierte en responsable de su propia vida, debe administrar óptimamente su capital estético, afectivo, psíquico, libidinal.

El proceso de individuación no es nuevo, desde la modernidad se inventó la ideología del 
individuo libre, autónomo y parecido a los demás; se colocó dentro de una economía libre fundada sobre la independencia del mercado, lo mismo que en regímenes democráticos. La diferencia es que la sociedad postmoderna entra en la cotidianidad con nuevas estrategias de autonomía individual.

La política no se encuentra separada de la seducción, el hombre político reconoce amablemente sus límites y sus debilidades, coloca en escena a su familia, declara no poder sacrificar su vida privada, sale por la TV con el perro que le regalaron o haciendo deporte en las calles. La política personalizada corresponde a la emergencia de los nuevos valores que son la cordialidad, las confidencias íntimas, la proximidad, la autenticidad, los valores individualistas-democráticos ofrecidos para la consumación en masa.

La seducción es hija del individualismo hedonista y del maquiavelismo político. Todo debe ser psicologizado, seres humanos, plantas, medio ambiente. El efecto, patrimonio es indisociable de la dulcificación de las costumbres, del sentimiento, de crecimiento del respeto y de la tolerancia y de una psicologización sin límites.

El cuerpo está integrado en la seducción. Hay que mostrar el cuerpo, cuidar el cuerpo y cada uno es responsable de él. Las experiencias vividas son las que valen. La emancipación, la búsqueda de la identidad pasa por la expresión y por la confrontación de experiencias existenciales.

Por consiguiente, dentro de una ambiente de seducción, la argumentación ética desde la objetividad y la neutralidad pierde mucho más piso. El comunicador cree justificarse desde el descubrimiento o desocultamiento de la verdad, olvidando algo tan fundamental para algunos filósofos: la verdad no se descubre, la verdad se inventa desde el poder.

1 GILLES, L., Ed. Seuil, Paris, p. 87

2 Ibíd. p. 32. 